\title{
Pelze, Gold und Weihwasser: Handel und Mission in Afrika UND AMERIKa
}

Reviewer:

Christoph Stenschke

\section{Affiliation:}

${ }^{1}$ Department of New

Testament and Early

Christian Studies,

University of South Africa,

PO Box 392, Pretoria, 0003

South Africa

\section{Correspondence to:}

Christoph Stenschke

e-mail:

cstenschke@freenet.de

\section{Postal address:}

Department of New

Testament and Early

Christian Studies,

University of South Africa,

PO Box 392, Pretoria, 0003 ,

South Africa

Keywords:

review; mission; history of mission; Africa; America

\section{Dates:}

Received: 01 July 2009

Accepted: 31 July 2009

Published: 02 Dec. 2009

How to cite this article: Stenschke, C., 2009, 'Pelze, Gold und Weihwasser: Handel und mission in Afrika und Amerika', Verbum et Ecclesia 30(2), Art. \#80, 2 pages. DOI: 10.4102/ ve.v30i2.80

\section{This article is available} at: http://www.ve.org.za
C 2009. The Authors. Licensee: OpenJournals Publishing. This work is licensed under the Creative Commons Attribution License.

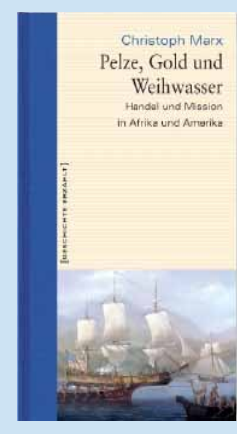

ISBN: 978-3-89678-334-9

Author: Christoph Marx

Published by: Primus Verlag

Postal address:

Primus Verlag GmbH

Postfach 101153

D-64211 Darmstadt

Germany

Tel: +496151318047

Fax: +4961513308208

e-mail: kontakt@primusverlag.de

Price: $€ 16,90$ online (correct at time of publishing this review)

Marx lehrt als Professor für außereuropäische Geschichte an der Universität Duisburg-Essen. Sein Spezialgebiet ist die Geschichte des südlichen Afrika. Das vorliegende Bändchen zeigt an vier Fallstudien die große Bandbreite der Begegnung europäischer Händler und Missionare (die Missionsträger dürften wohl deutlicher zwischen Händlern und Missionaren unterschieden haben als dies in der Wahrnehmung der Einheimischen der Fall war) mit anderen Kulturen in der Zeit vor der systematischen Kolonialisierung in unterschiedlichen Epochen, als noch nicht absehbar war, dass sich die Europäer durchsetzen würden. Marx zitiert immer wieder ausführlich aus den Quellen, die der Darstellung zugrundeliegen. Dabei wird die Sicht der anderen, soweit die Quellen dies erlauben, mit einbezogen. Marx beobachtet, dass

Die Begegnung mit Menschen aus anderen Kulturen die europäische Expansion beeinflusste. Denn die Europäer staunten über große Reiche in Asien, die reicher und kultivierter waren als ihre eigenen. Sie lernten unbekannte Religionen und Gesellschaften kennen, die sich in keines der vertrauten Muster einfügen ließen. Portugiesen und Spanier, später auch Niederländer, Franzosen und Briten, waren keineswegs so überlegen, wie sie sich einredeten, sondern mussten sich oft lokalen Verhältnissen anpassen und ihre wirtschafltichen Gewinnchancen für politische Unterwerfungsgesten einhandeln. Die Versuche, das Christentum zu verbreiten, stießen nicht nur bei Muslimen auf Ablehnung und Widerstand (8f).

Zuerst geht es um die Eroberungen der Portugiesen in Südostafrika (12-42). Die Portugiesen konnten sich zwar die Herrschaft an der Küste sichern (hier gingen Kolonisierung und Mission Hand in Hand), aber das soziale und politische Normengefüge der Karanga-Reiche im Landesinneren nicht aufbrechen. Das zeigt sich auch daran, dass die Mission nur im unmittelbaren Einflussbereich der Portugiesen Erfolge aufweisen konnte (42).

Dann untersucht Marx Pelzhandel und Missionare bei den Huronen im Gebiet der großen Seen Nordamerikas (43-74). Die Mission wurde wesentlich von französischen Jesuiten getragen. Zur Wirkung der Mission trugen neben der Destabilisierung der Gesellschaft verschiedene Epidemien bei, die viele Huronen tief verunsicherten: „Immer mehr Menschen begannen ihre Kosmologie in Zweifel zu ziehen und Alternativen zu akzeptieren. Die Todesorientiertheit der christlichen Botschaft, das Heilsversprechen im Jenseits und die Aussicht auf Wiederauferstehung, die in der huronischen Religion nicht vorkamen, erhielten unter dem Eindruck des Verlusts vieler Familienangehöriger eine neue Qualität und Verlockung" (69f).

Anschließend geht es unter der Überschrift „Der König und der Missionar: Die neue Welt der Ndebele" (75-104) um Robert Moffat und Mzilikazi, den König der Ndebele. Hier zeigt Marx u.a. die Wirkung der Schilderungen der Missionare auf die folgende Geschichtsschreibung (er spricht von „historiografischem Rufmord“). Der König war nicht sonderlich an der christlichen Botschaft intereriessert, doch die Missionare waren als Vermittler im Streit wichtig, stellten Kontakte zur Kapkolonie her und verschafften ihm Zugang zu westlichen Waren.

Abschließend geht es um Händler und Missionare an der kanadischen Westküste (105-135). Die dortigen Indianer waren ausgesprochen gewiefte Händler und den Weißen gegenüber in vieler Hinsicht im Vorteil. Die kulturellen Änderungen durch die Einführung neuer Werkzeuge, Kleidung und durch sich ändernde Bedürfnisse wurden zumindest in der Anfangsphase von den Indianern bestimmt (111).

Die Fallstudien zeigen, dass die Reiche, die man im "geschichtslosen“ Afrika ohnehin nicht vermutete, die Europäer für ihre Zwecke nutzten, die Missionare auf Abstand hielten und sich als den weißen Kaufleuten ebenbürtige Partner erwiesen. Ferner wird deutlich, dass die Begegnungen teilweise von unfreiwilliger Komik waren. Der Umgang miteinander blieb auf beiden Seiten von anhaltendem Misstrauen bestimmt; die Kontakte wurden hauptsächlich vom Interesse an den Waren des jeweils anderen aufrechterhalten.

Im Handel mit den Europäern beherrschten die Einheimischen alle Tricks des Handels, von dem sie ebenso profitierten wie die Europäer (137). Sie waren zu eigenständigem und wohlüberlegtem Handeln 
in der Lage. Nach Marx ist daher eine Geschichtsschreibung, die diese Menschen ausblendet und nur die Europäer als gute oder böse Täter im Blick hat, öde und langweilig (137). Diese Fallstudien zeigen die bescheidenen Erfolge der Mission vor oder in der Anfangsphase der Kolonialisierung. Eine Ausnahme in der Darstellung bilden die Bestrebungen der Portugiesen in Südostafrika (siehe oben). Die europäische Expansion war von den Leitmotiven Handel und Mission bestimmt: „Von ihrem Ausgangspunkt in der Feindschaft gegen den Islam und der Suche nach Gold für die innereuropäischen Kriege bis hin zum privaten Glück der Goldsucher und dem jenseitigen frommer Missionare" (11). Die Würdigung des konkreten Handelns der Missionare ist durchweg kritisch aber zumeist nachvollziehbar. Die Analyse der Motive der Missionare ist hingegen unbefriedigend. Marx' Darstellung ist ernüchternd und zeigt ein anderes Bild als manche, vor allem ältere, missionsgeschichtliche Darstellung. Sie ist daher eine wichtige Ergänzung zu missionsgeschichtlichen Gesamtdarstellungen oder Einzelstudien.

Marx' Fallstudien eignen sich auch für den Unterricht. Sie werfen interessante und wichtige Fragen für die Missionsgeschichte und Missionspraxis auf und sensibilisieren für die Perspektive der Einheimischen sowie die Rolle der Missionsgeschichtsschreibung. 